Jannis Harjus

Sociofonética andaluza y lingüística perceptiva de la variación: el español hablado en Jerez de la Frontera 


\section{Lengua y Sociedad en el Mundo Hispánico Language and Society in the Hispanic World}

Editado por / Edited by:

Julio Calvo Pérez (Universidad de Valencia)

Anna María Escobar (University of Illinois at Urbana-Champaign)

Luis Fernando Lara (El Colegio de México)

Francisco Moreno Fernández (Universidad de Alcalá de Henares

/ Instituto Cervantes at Harvard University)

Juan Pedro Sánchez Méndez (Université Neuchâtel)

Armin Schwegler (University of California, Irvine)

José del Valle (The Graduate Center-CUNY)

Klaus Zimmermann (Universität Bremen)

Vol. 38 


\author{
Jannis Harjus
}

\title{
Sociofonética andaluza
}

y lingüística perceptiva de la variación: el español hablado en Jerez de la Frontera 
Cualquier forma de reproducción, distribución, comunicación pública o transformación de esta obra solo puede ser realizada con la autorización de sus titulares, salvo excepción prevista por la ley. Diríjase a CEDRO (Centro Español de Derechos Reprográficos) si necesita fotocopiar o escanear algún fragmento de esta obra (www.conlicencia.com; $917021970 / 932720447)$

Reservados todos los derechos

(C) Iberoamericana, 2018

Amor de Dios, 1 - E-28014 Madrid

Tel.: +34914293522

Fax: +34914295397

(C) Vervuert, 2018

Elisabethenstr. 3-9 - D-60594 Frankfurt am Main

Tel.: +49695974617

Fax: +49695978743

info@iberoamericanalibros.com

www.iberoamericana-vervuert.es

ISBN 978-84-16922-69-7 (Iberoamericana)

ISBN 978-3-95487-722-5 (Vervuert)

ISBN 978-3-95487-723-2 (e-Book)

Diseño de la cubierta: Carlos Zamora 
Con mucho aprecio a la maravillosa ciudad de Jerez y a sus amables habitantes

Für Linda, el amor de mi vida Für meine Eltern, in Liebe und Dankbarkeit Para Ale, mi gran amigo andaluz 
